\title{
Phase Behavior of Aqueous Biphasic Systems with Choline Alkanoate Ionic Liquids and Phosphate Solutions: The Influence of $\mathrm{pH}$
}

\author{
Paula Berton $1,2 \mathbb{D}$, Hongzhe Tian ${ }^{1,3, *}$ and Robin D. Rogers $1,4, * \mathbb{D}$ \\ 1 Department of Chemistry, McGill University, 801 Sherbrooke St. West, Montreal, QC H3A 0B8, Canada; \\ paula.berton@ucalgary.ca \\ 2 Chemical and Petroleum Engineering Department, University of Calgary, 2500 University Drive NW, \\ Calgary, AB T2N 1N4, Canada \\ 3 Plant Protection College, Shenyang Agricultural University, 120 Dongling Road, Shenyang 110161, China \\ 4525 Solutions Inc., P.O. Box 2206, Tuscaloosa, AL 35403, USA \\ * Correspondence: tianhongzhe@syau.edu.cn (H.T.); Robin.Rogers@525Solutions.com (R.D.R.)
}

Citation: Berton, P.; Tian, H.; Rogers, R.D. Phase Behavior of Aqueous Biphasic Systems with Choline Alkanoate Ionic Liquids and Phosphate Solutions: The Influence of pH. Molecules 2021, 26, 1702. https:// doi.org/10.3390/molecules26061702

Academic Editor: João Paulo Leal

Received: 7 February 2021

Accepted: 15 March 2021

Published: 18 March 2021

Publisher's Note: MDPI stays neutral with regard to jurisdictional claims in published maps and institutional affiliations.

Copyright: (c) 2021 by the authors. Licensee MDPI, Basel, Switzerland. This article is an open access article distributed under the terms and conditions of the Creative Commons Attribution (CC BY) license (https:// creativecommons.org/licenses/by/ $4.0 /)$.

\begin{abstract}
Aqueous biphasic systems (ABS) composed of the choline alkanoate ionic liquids (ILs) choline acetate [Cho][OAc], choline propanoate [Cho][Pro], choline butyrate [Cho][But], and choline hexanoate [Cho][Hex], mixed with $\mathrm{K}_{3} \mathrm{PO}_{4}$ solutions at $\mathrm{pH} 7.2$ and 14.5, were prepared and their phase diagrams were compared. The ability to form $\mathrm{ABS}$ with alkaline $\mathrm{K}_{3} \mathrm{PO}_{4}$ solutions decreased in the order $[\mathrm{Cho}][\mathrm{OAc}] \approx[\mathrm{Cho}][\mathrm{Pro}]>[\mathrm{Cho}][\mathrm{But}]>[\mathrm{Cho}][\mathrm{Hex}]$, while with neutral $\mathrm{K}_{3} \mathrm{PO}_{4}$ solutions, [Cho][OAc] could not form an ABS, and the other three ILs performed similarly. All of the biphasic regions of the ABS decreased with the increase in $\mathrm{pH} .{ }^{1} \mathrm{H}-\mathrm{NMR}$ data indicated anion exchange between phases in ABS at neutral $\mathrm{pH}$. The ABS at neutral $\mathrm{pH}$ were evaluated to extract the triazine herbicides simazine, cyanazine, and atrazine, and the ABS formed by [Cho][Pro] and the $\mathrm{pH} 7.2$ $\mathrm{K}_{3} \mathrm{PO}_{4}$ solution has shown extraction recoveries higher than $90 \%$.
\end{abstract}

Keywords: aqueous biphasic system; choline alkanoate ionic liquid; $\mathrm{pH}$ effect; phosphate solution; triazine-based herbicides

\section{Introduction}

Aqueous biphasic systems (ABS) are, as the name implies, two-phase systems mainly composed of water. The aqueous nature of the two phases, without using volatile organic solvents, suggests that these systems could be more environmentally friendly alternatives for traditional liquid-liquid extraction methods. ABS have been reported for extractions of organic compounds [1-6] and biological macromolecules [7-10]. Based on their components, these systems can be classified as polymer/salt, polymer/polymer, ionic liquid (IL)/polymer, IL/salt, and IL/surfactant. The ABS based on polymers generate systems with high viscosity, which can be a drawback in extraction processes. Therefore, ABS with salts and ILs are preferable choices and by their nature have more tunable properties [11].

Ionic liquids, defined as organic salts with melting points below $100{ }^{\circ} \mathrm{C}$ [12], are salts that can be designed to have tunable properties for specific applications, including sample pretreatment and analyte extraction [13]. At present, most of the ABS with salts and ILs focus on systems with imidazolium-based ILs and inorganic salts [14,15]; however, some of the imidazolium-based ILs can have negative impacts on the environment and organisms [16,17]. Therefore, it is very important to design ABS based on biocompatible, environmentally friendly ILs.

Choline-based ILs are biodegradable, present low toxicity, are readily available, and have a low cost [18-22]. However, due to their high affinity for water, these ILs are usually studied in combination with polyethylene glycol (PEG) or polypropylene glycol (PPG) 
to form ABS [23-27]. On the other hand, there is only a limited number of reports about choline-based ILs applied to develop ABS with inorganic or organic salts [28-31].

Many factors influence the formation of ABS by ILs and salts, such as the nature of the ions, mass fractions, $\mathrm{pH}$, and temperature. Among these, when ABS are used in extraction processes, it is very important to examine the effect of $\mathrm{pH}$, not only on the ABS formation, but also on the analytes themselves. For example, the $\mathrm{pH}$ can affect the electrostatic and hydrophobic interactions in the target proteins and thus influence their extraction recoveries by ABS [8,10,32-39]. However, the effect of $\mathrm{pH}$ on ABS formation with choline-based ILs and salts is scarcely studied [28], since it is relatively difficult to create ABS using choline-based ILs with salts.

It has been reported that high charge density salts, such as $\mathrm{K}_{3} \mathrm{PO}_{4}$ [28], can be used to overcome the high hydrophilicity of choline-based ILs and form ABS. However, the alkaline nature of the resulting ABS limits its application to the extraction of organic pollutants. It is reported that neutral phosphate buffer solution and neutral citrate buffer solution could salt out choline salicylate and benzyldimethyl(2-hydroxyethyl)ammonium chloride to form an ABS [28]. Ideally, the ABS should be formed using choline-based ILs and neutral buffer solutions for extractions.

Choline alkanoate ILs are environmentally friendly and easily biodegradable [19], have been used to induce ABS formation with polymers [23,26,40,41], and have shown good performance for extracting plant biocomposites [42,43]. In this work, we explore using choline acetate [Cho][OAc], choline propanoate [Cho][Pro], choline butyrate [Cho][But], choline hexanoate [Cho][Hex], and choline octanoate [Cho][Oct] in combination with $\mathrm{K}_{3} \mathrm{PO}_{4}$ solutions to form ABS at neutral (7.2) or alkaline (14.5) $\mathrm{pH}$. Phase diagrams and a deep characterization using Nuclear Magnetic Resonance (NMR) spectroscopy are presented. Continuing our efforts to utilize ABS for the extraction of triazine-based herbicides [44,45], we also show the applicability of these ABS to the determination of these analytes.

\section{Results and Discussion}

Using the procedure described in the experimental section for the determination of the phase diagrams, a screening step was initially conducted to select the proper phosphate salt able to generate ABS with choline alkanoate ILs. Various aqueous phosphate solutions (Table 1) were added to the aqueous solutions of the ILs to form cloudy or clear solutions. The results indicated that the choline alkanoate ILs could not be salted out by sodiumbased salts, irrespective of the phosphate speciation induced by $\mathrm{pH}$ changes. On the other hand, $\mathrm{K}_{3} \mathrm{PO}_{4}$ solutions adjusted to $\mathrm{pH} 7.2$ or 14.5 salted out [Cho][Pro], [Cho][But], and [Cho][Hex], while no ABS could be formed with [Cho][Oct], irrespective of the $\mathrm{pH}$ or salt used. Phosphate salt precipitated in the system formed with [Cho][Oct] under neutral $\mathrm{pH}$ conditions, but no salting out was observed using the same IL under alkaline conditions. [Cho][OAc] could be salted out at $\mathrm{pH} 14.5$, but not at $\mathrm{pH}$ 7.2. Out of the ILs tested in this work, only [Cho][OAc] was previously reported to form $\mathrm{ABS}$ in combination with $\mathrm{K}_{3} \mathrm{PO}_{4}$ under alkaline conditions $(\mathrm{pH}>12)$ [28], resulting in a phase diagram and binodal curves similar to the ones reported in this work.

The binodal curves for the seven possible ABS were then constructed by cloud point titration of $80 \mathrm{wt} \%$ aqueous solutions of [Cho][OAc], [Cho][Pro], [Cho][But], and [Cho][Hex] mixed with aqueous $\mathrm{K}_{3} \mathrm{PO}_{4}$ solutions at $\mathrm{pH} 14.5$ or 7.2. The alkaline phosphate solution was prepared by directly adding the appropriate amount of $\mathrm{K}_{3} \mathrm{PO}_{4}$ into deionized (DI) water, while the neutral phosphate solution was formed by mixing the appropriate amount of $\mathrm{K}_{3} \mathrm{PO}_{4}$ and $\mathrm{H}_{3} \mathrm{PO}_{4}$ with DI water. The phosphate solution was then dripped into the IL solution to form cloudy solutions, and water was then added to clarify the solutions. The procedure was repeated and the mass fractions of IL and $\mathrm{K}_{3} \mathrm{PO}_{4}$ were recorded to establish the phase diagrams. 
Table 1. Aqueous biphasic systems (ABS) formation by choline alkanoate ionic liquids (ILs) and different phosphate solutions ${ }^{1}$.

\begin{tabular}{|c|c|c|c|c|c|}
\hline & [Cho][OAc] & [Cho][Pro] & [Cho][But] & [Cho][Hex] & [Cho][Oct] \\
\hline $\begin{array}{c}\mathrm{K}_{3} \mathrm{PO}_{4} \\
(\mathrm{pH} 14.5)\end{array}$ & $\checkmark$ & $\checkmark$ & $\checkmark$ & $\checkmark$ & $x$ \\
\hline $\begin{array}{c}\mathrm{K}_{3} \mathrm{PO}_{4} \\
(\mathrm{pH} 7.2)\end{array}$ & $x$ & $\checkmark$ & $\checkmark$ & $\checkmark$ & $x$ \\
\hline $\begin{array}{l}\mathrm{Na}_{2} \mathrm{HPO}_{4} \\
(\mathrm{pH} 9.0)\end{array}$ & $x$ & $x$ & $x$ & $x$ & $x$ \\
\hline $\begin{array}{l}\mathrm{NaH}_{2} \mathrm{PO}_{4} \\
(\mathrm{pH} 3.3)\end{array}$ & $x$ & $x$ & $x$ & $x$ & $x$ \\
\hline $\begin{array}{c}\mathrm{NaH}_{2} \mathrm{PO}_{4} / \mathrm{Na}_{2} \mathrm{HPO}_{4} \\
(\mathrm{pH} 5.5)\end{array}$ & $x$ & $x$ & $x$ & $x$ & $x$ \\
\hline $\begin{array}{c}\mathrm{NaH}_{2} \mathrm{PO}_{4} / \mathrm{Na}_{2} \mathrm{HPO}_{4} \\
(\mathrm{pH} 7.0)\end{array}$ & $x$ & $x$ & $x$ & $x$ & $x$ \\
\hline
\end{tabular}

The binodal curves at room temperature are presented in Figure 1 and the binodal data are provided in the Supplementary Materials (SM). The phase forming ability with the $\mathrm{K}_{3} \mathrm{PO}_{4} \mathrm{pH} 14.5$ solutions decreased (i.e., it took higher concentrations of the inorganic salt to form an ABS) in the order [Cho][OAc] $\approx[\mathrm{Cho}][\mathrm{Pro}]>[\mathrm{Cho}][\mathrm{But}]>[\mathrm{Cho}][\mathrm{Hex}]$. It was previously reported that an increase in the imidazolium cation alkyl chain length leads to an increase in the IL's hydrophobic nature and therefore to a poorer affinity for water and a greater ability of the IL to form an ABS [46]. Our observations indicate that the larger the alkyl chain in the anion, the harder it was to form an $\mathrm{ABS}$ at basic $\mathrm{pH}$, leading to the point where no ABS was formed with [Cho][Oct]. When $\mathrm{K}_{3} \mathrm{PO}_{4} \mathrm{pH} 7.2$ solutions were used, [Cho][Pro], [Cho][But], and [Cho][Hex] were more easily salted out and all exhibited essentially the same ability to form two phases. If the phase diagram is represented using the phosphate anion (instead of $\mathrm{K}_{3} \mathrm{PO}_{4}$ ) as the horizontal axis, the phase-forming ability of the selected ionic liquids follows the same pattern, although the effect of the $\mathrm{pH}$ is weaker (Figure S3 in the Supplementary Materials). No differences in ABS forming ability were observed for [Cho][Pro] with respect to $\mathrm{pH}$, but the ILs [Cho][But] and [Cho][Hex] were salted out more easily at neutral $\mathrm{pH}$.

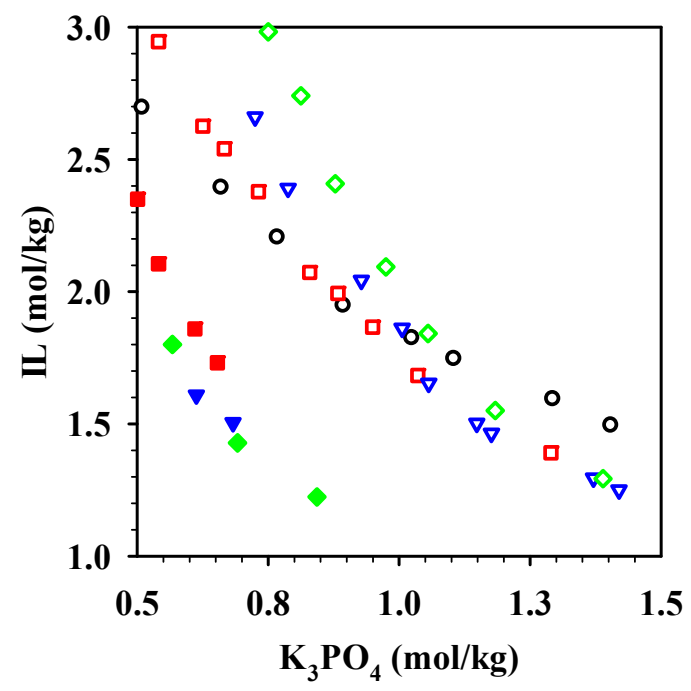

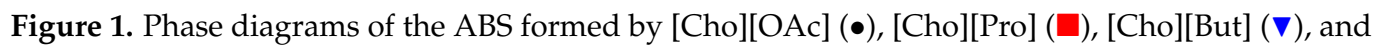
[Cho][Hex] $(\diamond)$ with $\mathrm{K}_{3} \mathrm{PO}_{4}$ at $\mathrm{pH} 7.2$ (filled symbols) and $\mathrm{pH} 14.5$ (open symbols). The full phase diagram is included in Supplementary Materials Figure S2. 
It has typically been reported that salt anions have the greatest effect on a salt's ability to salt out or be salted out $[47,48]$, and the results here suggest that some protonation of the IL anions occurs at the higher $\mathrm{pH}$, since the ILs would be considered the kosmotropic (salted out) salts. Prior reports focusing on the protonation of the kosmotropic (salting out) salts (citrate buffer solutions, $\mathrm{pH}$ 5-8) indicate that it is easier to salt out imidazoliumor quaternary ammonium-based ILs by increasing $\mathrm{pH}$ of the aqueous solution due to the degree of protonation of the citrate ions at different $\mathrm{pH}[49,50]$. The previous literature also indicates that ABS form more easily under alkaline conditions rather than acidic or neutral conditions [51,52]. At alkali conditions, we observe that the $\mathrm{PO}_{4}{ }^{3-}$ anion is able to salt out all the [Cho]-based ILs, except for [Cho][Oct]. However, larger concentrations of the $\mathrm{PO}_{4}{ }^{3-}$ anion are needed to form ABS (i.e., a decrease in salting out ability) at higher $\mathrm{pH}$.

This discrepancy might be due to the higher complexity of our systems, with protic salts salting out other protic salts. The speciation of the phosphate salt changes from a $\mathrm{H}_{2} \mathrm{PO}_{4}{ }^{-} / \mathrm{HPO}_{4}{ }^{2-}$ system at $\mathrm{pH} 7.2$ to $\mathrm{PO}_{4}{ }^{3-}$ at $\mathrm{pH} 14.5$ [53]. In addition, the hydroxide group present in the choline cation is protonated at $\mathrm{pH} 7.2$ but deprotonated (i.e., presents a negative charge) at $\mathrm{pH} 14.5$ (pKa 13.9) [54], while the anions of the ILs are weak organic carboxylic acids that, at both neutral and alkaline $\mathrm{pH}$, are in their anionic forms ( $\mathrm{pKa}$ values: $4.75-4.90$ ) [55].

To further study the effect of solution $\mathrm{pH}$ on the speciation of IL anions, we conducted ${ }^{1} \mathrm{H}-\mathrm{NMR}$ studies of [Cho][Pro], its aqueous solutions, and the separated phases of ABS formed with $\mathrm{K}_{3} \mathrm{PO}_{4}$ solutions adjusted to $\mathrm{pH} 7.2$ and 14.5. First, [Cho][Pro] was diluted with water to make 10-57 $\mathrm{wt} \%$ [Cho][Pro] aqueous solutions and the NMR spectra of the resulting solutions were taken using an external standard. The chemical shift deviations $(\Delta \delta$, see Experimental section, Equation (2)) were calculated as the change in $\delta$ compared to the pure IL [Cho][Pro] (Figure 2).

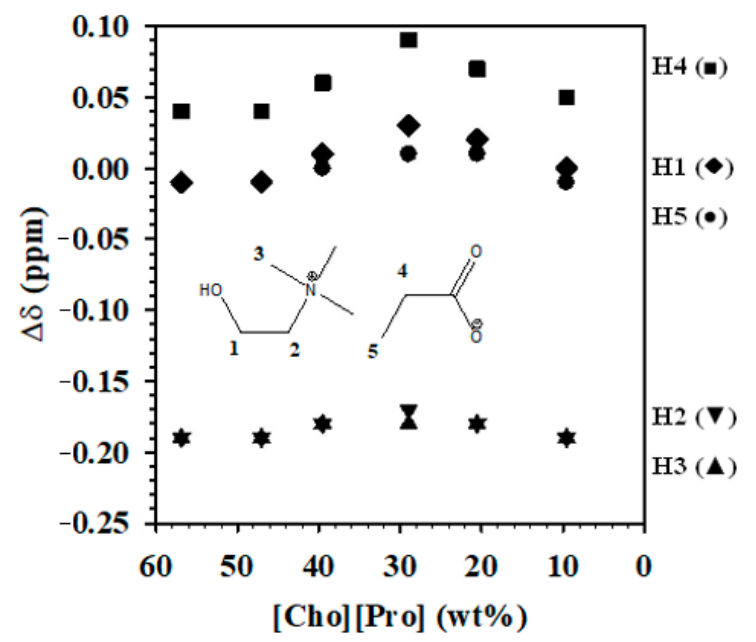

Figure 2. Chemical shift deviation of the protons (H1 $(\bullet), \mathrm{H} 2(\boldsymbol{\nabla}), \mathrm{H} 3(\boldsymbol{\Delta}), \mathrm{H} 4(\boldsymbol{\square}), \mathrm{H} 5(\bullet)$ following the numeration indicated in the IL formula overlapped in the figure) in aqueous solutions of [Cho][Pro] compared to pure [Cho][Pro]. Note that the chemical shifts of $\mathrm{H} 2$ and $\mathrm{H} 3$ overlap.

Water has the largest influence on the hydrogen atoms in the cation residing on $\mathrm{C}$ atoms directly bonded to the $\mathrm{N}(\mathrm{H} 3, \mathrm{H} 2)$. At $40 \mathrm{wt} \%$ water $\left(60 \mathrm{wt} \% \mathrm{IL}, \sim 7.5 \mathrm{H}_{2} \mathrm{O}: \mathrm{IL} \mathrm{mol}\right.$ ratio), these atoms experience a negative deviation of approximately -0.2 , while the $\mathrm{H} 4$ hydrogen atoms in the anion on the $\mathrm{C}$ bonded to the carboxylate group exhibit the largest positive deviation of approximately 0.05 . The $\mathrm{H}$ atoms on $\mathrm{C}$ atoms further away from the charge bearing groups are much less affected with essentially no or very little change in chemical shift. Interestingly, as the water concentration increases, all of the chemical shift deviations become more positive until $70 \mathrm{wt} \%$ (i.e., $30 \mathrm{wt} \% \mathrm{IL}, \sim 64.5 \mathrm{H}_{2} \mathrm{O}: \mathrm{IL}$ mol ratio), where they turn more negative, eventually ending up nearly the same as they were with only $40 \%$ water. 
NMR studies were also conducted on the separated phases of the [Cho][Pro] $/ \mathrm{K}_{3} \mathrm{PO}_{4}$ ( $\mathrm{pH} 7.2$ and 14.5) ABS. Three mixtures in the biphasic regions of the ABS formed under different $\mathrm{pH}$ were prepared by mixing $\mathrm{K}_{3} \mathrm{PO}_{4}$ solution and aqueous [Cho][Pro] solution, in which the mass fraction of $\mathrm{K}_{3} \mathrm{PO}_{4}$ was approximately $10.0 \mathrm{wt} \%$ at $\mathrm{pH} 7.2$ or approximately $15.0 \mathrm{wt} \%$ at $\mathrm{pH} 14.5$, while [Cho][Pro] concentrations were approximately 35,40 , or $45 \mathrm{wt} \%$, respectively. The selected overall compositions are marked in red (Figure 3), overlaid on the binodal curves for these two ABS (tie-line data included in Supplementary Materials Figure S4). After phase separation, the $\mathrm{pH}$ of each phase (the top, IL-rich phase and the bottom, $\mathrm{K}_{3} \mathrm{PO}_{4}$-rich phase) was measured (Table $\mathrm{S} 3$ in the Supplementary Materials): When the neutral $\mathrm{pH}$ solution was used to generate the ABS, the resulting phases were weakly alkaline ( $\mathrm{pH} 8.08-8.47)$, with a slightly higher $\mathrm{pH}$ on the top phase (8.35-8.47) than on the bottom phase (8.08-8.20), possibly indicating ion exchange among the phases. On the other hand, the two phases of the ABS formed by alkaline $\mathrm{K}_{3} \mathrm{PO}_{4}$ solution remained strongly alkaline ( $\mathrm{pH}$ 13.50-14.42), with a slightly lower $\mathrm{pH}$ on the top phase (13.50-13.81) than on the bottom phase (14.20-14.42). In addition, the NMR spectra of the top and bottom phases of the ABS were measured (shown in the Supplementary Materials).

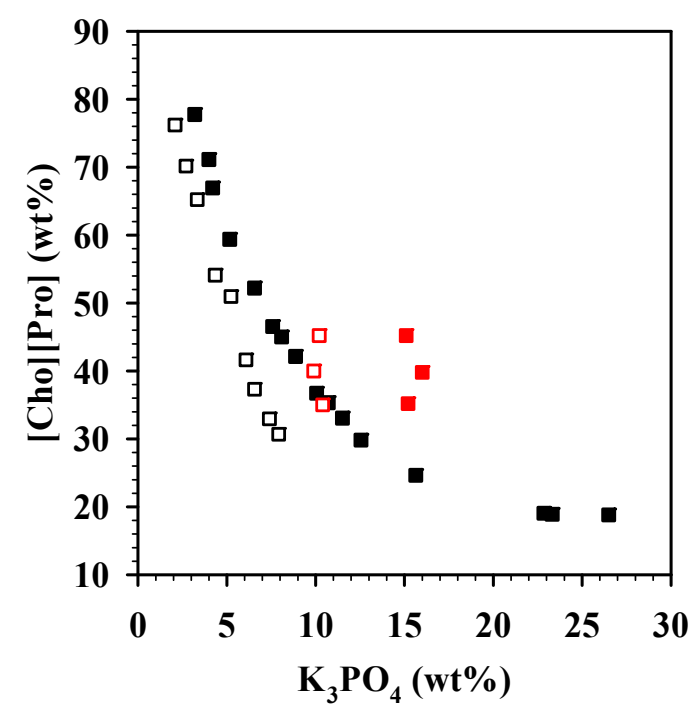

Figure 3. Binodal curves for [Cho][Pro] $/ \mathrm{K}_{3} \mathrm{PO}_{4} \mathrm{ABS}$ (shown in wt $\%$; compare with Figure 1 ) at $\mathrm{pH}$ 7.2 (open symbols) and 14.5 (filled symbols) with the overall compositions used for the NMR study (red symbols). Tie-line data is included in Supplementary Materials Figure S4.

The NMR data of the phases formed from the [Cho][Pro] $/ \mathrm{K}_{3} \mathrm{PO}_{4} \mathrm{ABS}$ at different $\mathrm{pH}$ values were first used to follow the fate of the IL's components. The ratio of the integral areas of the protons of the IL's component ions was used to determine the $\left[\mathrm{Cho}^{+}:[\mathrm{Pro}]^{-}\right.$ratio in the two phases (Table S4, Supplementary Materials). The cation:anion ratio remained approximately 1:1 in all of the top phases (IL-rich phases) of the ABS evaluated, irrespective of the $\mathrm{pH}$ of the solution and the IL concentration. The 1:1 cation:anion composition was also observed in the bottom phases of the systems at $\mathrm{pH} 14.5$, while in the bottom phases $\left(\mathrm{K}_{3} \mathrm{PO}_{4}\right.$-rich phase) of the systems at $\mathrm{pH} 7.2$, the concentration of $[\mathrm{Pro}]^{-}$with respect to $[\mathrm{Cho}]^{+}$decreased dramatically, indicating some ion exchange between the phases at neutral $\mathrm{pH}$.

The NMR data were also used to calculate the chemical shift deviations of the protons of [Cho][Pro] in the top and bottom phases of the [Cho][Pro] $/ \mathrm{K}_{3} \mathrm{PO}_{4} \mathrm{ABS}$ at $\mathrm{pH} 7.2$ and 14.5 (Figure 4). The chemical shift deviation of all protons in the two phases was negative, which is different from the positive deviation of $\mathrm{H} 5$ and $\mathrm{H} 1 \mathrm{in}$ [Cho][Pro] aqueous solution, indicating the strong influence of the phosphate anions in the system. 


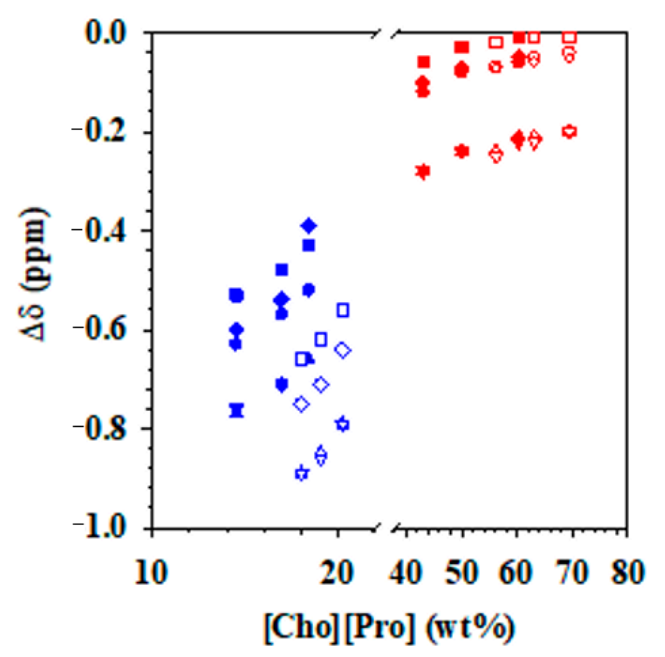

Figure 4. Chemical shift deviations of the protons in the top, [Cho][Pro]-rich phase (red) and the bottom, $\mathrm{K}_{3} \mathrm{PO}_{4}$-rich phase (blue) of the ABS with [Cho][Pro] and $\mathrm{K}_{3} \mathrm{PO}_{4}$ at $\mathrm{pH} 7.2$ (filled symbols) and pH 14.5 (open symbols): H1 $(\bullet), \mathrm{H} 2(\boldsymbol{\nabla}), \mathrm{H} 3(\boldsymbol{\Delta}), \mathrm{H} 4(\boldsymbol{\square}), \mathrm{H} 5(\bullet)$, following the numeration indicated in Figure 3.

In the top phases of the two ABS (Figure 4, red symbols), a downfield chemical shift deviation (negative $\Delta \delta$ values in comparison to pure IL) was observed for all of the groups of protons (H1 to H5) at low IL concentrations. This negative deviation decreased with the increase in IL concentration, and reached a plateau at $60 \mathrm{wt} \%$ IL. Comparing the deviations of the protons of the ILs in the ABS formed with alkaline solutions (Figure 4, red, open symbols) to those at neutral $\mathrm{pH}$ (Figure 4, red, filled symbols) indicates that the main differences are based on IL concentration rather than other effects due to the $\mathrm{pH}$. The highest deviation was observed for proton $\mathrm{H} 3$ and $\mathrm{H} 2$; both protons are located in the cation. These two protons seem to interact with the water molecules at low IL concentrations, interactions that seem to decrease at higher concentrations of IL, possibly due to the formation of oligomeric ions, which is a characteristic of protic ILs.

An analysis of the protons in the bottom phases of the two [Cho] [Pro] $/ \mathrm{K}_{3} \mathrm{PO}_{4} \mathrm{ABS}$ (Figure 4, blue symbols) indicates a downfield chemical shift deviation, i.e., the same behavior observed in the top phase but with more negative $\Delta \delta$ values. As described for the top phases, the shifts decrease with the increase of IL concentration, and this decrease is linear except for the $\mathrm{H} 1$ protons in the $\mathrm{pH}$ 7.2 ABS. Also, as previously described for the protons in the top phase, the $\mathrm{H} 2$ and $\mathrm{H} 3$ protons suffer the highest negative shift. Different from what was observed in the top phases, $\mathrm{pH}$ has a greater influence on the proton deviation, with much larger negative deviations in the system at $\mathrm{pH} 14.5$ (Figure 4, blue, open symbols) than those observed in the protons of the system at pH 7.2 (Figure 4, blue, filled symbols). This difference is possibly due to the favorable interaction between the ions of the IL and water in the ABS at high $\mathrm{pH}$, where the hydroxide of the choline alkyl chain is also in its negative form, forming strong ionic hydrogen-bonded complexes with water.

The NMR data of the phases formed from the [Cho][But] $/ \mathrm{K}_{3} \mathrm{PO}_{4} \mathrm{ABS}$ at different $\mathrm{pH}$ values were also collected and used to follow the fate of the IL's components. Similar to what was observed for the $[\mathrm{Cho}][\mathrm{Pro}] / \mathrm{K}_{3} \mathrm{PO}_{4} \mathrm{ABS}$ systems, the $[\mathrm{Cho}]^{+}:[\mathrm{But}]^{-}$ratio remained approximately 1:1 in all the top phases of the ABS evaluated, but in the bottom phases of the systems, the concentration of [But $]^{-}$with respect to $[\mathrm{Cho}]^{+}$decreased dramatically, indicating ion exchange between the phases (Table S4, Supplementary Materials). Different from what was observed with the [Pro]-based ABS, the [But]-based ABS showed a significant decrease in anions in the bottom phase, irrespective of the $\mathrm{pH}$ of the solution and the IL concentration.

The NMR data were also used to calculate the chemical shift deviations of the protons of [Cho][But] in the top and bottom phases of the [Cho][But] $/ \mathrm{K}_{3} \mathrm{PO}_{4} \mathrm{ABS}$ at $\mathrm{pH} 7.2$ and 
14.5 (Figure 5). A downfield chemical shift deviation (negative $\Delta \delta$ values in comparison to pure IL) was observed for all protons (H1 to H5) in the two phases, with the largest deviations observed for proton $\mathrm{H} 3$ and $\mathrm{H} 2$, as observed in the [Pro]-based ABS. In the top phases of the two ABS (Figure 5, red symbols), this negative deviation slightly decreased with the increase in IL concentration. The deviations were slightly larger for the protons of the ILs in ABS formed with neutral pH (Figure 5, red filled symbols) in comparison to those observed in alkaline solutions (Figure 5, red open symbols). The protons in the bottom phases of the [Cho][But] $/ \mathrm{K}_{3} \mathrm{PO}_{4} \mathrm{ABS}$ (Figure 5, blue symbols) also showed more negative $\Delta \delta$ values than those in top phases. Also, as previously described for the protons in the top phase, the $\mathrm{H} 2$ and $\mathrm{H} 3$ protons suffer the highest negative shift. Different from what was observed in the top phases, $\mathrm{pH}$ did not have an influence on the proton deviation; it seemed to be more influenced by the IL concentration than by the $\mathrm{pH}$ of the solution ( $\mathrm{pH}$ 14.5, Figure 5, blue open symbols, or pH 7.2, Figure 5, blue filled symbols).

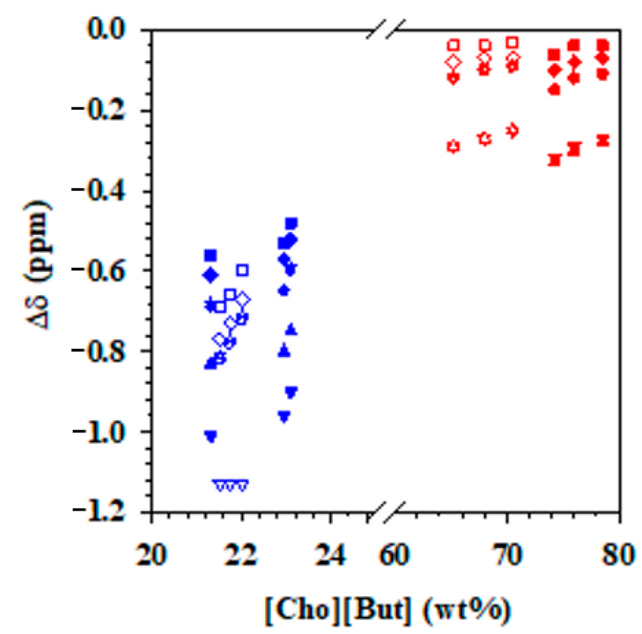

Figure 5. Chemical shift deviations of the protons in the top, [Cho][But]-rich phase (red) and the bottom, $\mathrm{K}_{3} \mathrm{PO}_{4}$-rich phase (blue) of the $\mathrm{ABS}$ with [Cho][But] and $\mathrm{K}_{3} \mathrm{PO}_{4}$ at $\mathrm{pH} 7.2$ (filled symbols) and pH 14.5 (open symbols): H1 $(\bullet), \mathrm{H} 2(\boldsymbol{\nabla}), \mathrm{H} 3(\boldsymbol{\Delta}), \mathrm{H} 4(\boldsymbol{\square}), \mathrm{H} 5(\bullet), \mathrm{H} 6(\star)$, following the numeration indicated in Table 3.

The proton behaviors in the upper and lower phases of the [Cho][Hex]/ $\mathrm{K}_{3} \mathrm{PO}_{4} \mathrm{ABS}$ were not analyzed since the IL components were not detected in the bottom phases (Figure S10, Supplementary Materials).

\section{Extraction of Triazine Herbicides Using Choline Alkanoate $/ \mathrm{K}_{3} \mathrm{PO}_{4}$ ( $p H$ 7.5) ABS}

Triazine-based herbicides such as simazine, cyanazine, and atrazine are reported to be unstable in strong acid or alkaline solutions [56]. Hence, we examined ABS comprised of [Cho][Pro], [Cho][But], and [Cho][Hex] with neutral $\mathrm{K}_{3} \mathrm{PO}_{4}$ solution to extract these herbicides while avoiding their degradation due to $\mathrm{pH}$.

In addition to the stability of the analytes and the extraction efficiency, the viscosity of the system was another parameter to consider, since it could interfere with the mass transfer of the analytes. Hence, the viscosity of the aqueous solutions with different IL concentrations was determined (Table S5, Supplementary Materials). Although, as expected, the viscosity of the solutions increased with increasing concentrations of the IL, the viscosity values were still relatively low, even at relatively high concentrations (e.g., at over $50 \% \mathrm{IL}$, viscosities were only $10-12 \mathrm{cP}$ ). Given these results, mass transfer of the analytes during extraction should not be significantly influenced by viscosity, and fast phase equilibrium is expected, which is beneficial for the partition of the analytes between the two phases.

The ABS were prepared with $10 \mathrm{wt} \% \mathrm{~K}_{3} \mathrm{PO}_{4}$ (pH 7.5) and variable amounts (35-45 wt \%) of [Cho][Pro], [Cho][But], and [Cho][Hex] spiked with $4.0 \mu \mathrm{g} / \mathrm{g}$ of the herbicide mixture 
(Figure 6). After equilibration, the two phases were separated, and the herbicides were quantified using High Performance Liquid Chromatography (HPLC). In all cases, the concentrations of the herbicides that remained in the lower, $\mathrm{K}_{3} \mathrm{PO}_{4}$-rich phases of the $\mathrm{ABS}$ after extraction were below the detection limit of the HPLC, indicating high partition coefficients to the upper, IL-rich phases. Therefore, the recoveries of the herbicides extracted by the different ABS were calculated by measuring the concentration of the herbicides in the IL-rich phase (extracting phase) to evaluate the extraction efficiency of the ABS (Table 2).

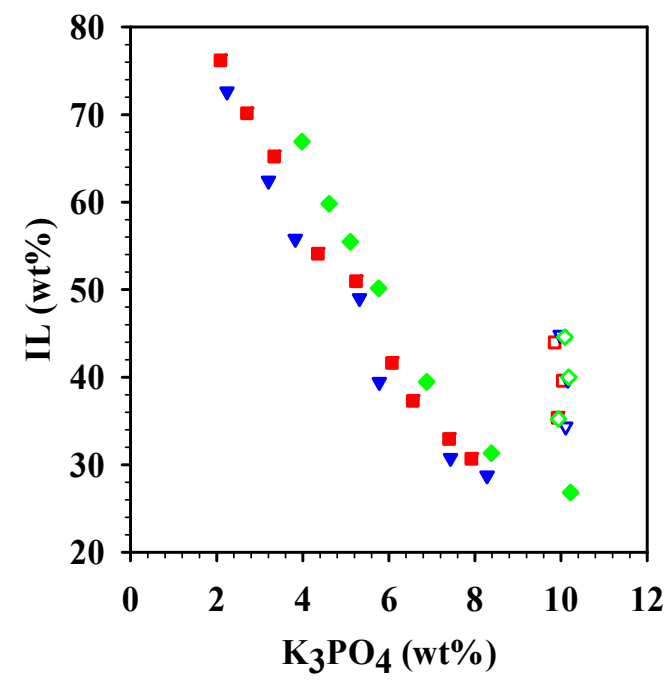

Figure 6. Binodal curves for ABS made with $[\mathrm{Cho}][\mathrm{Pro}](\square)$, [Cho][But] $(\nabla)$, and $[\mathrm{Cho}][\mathrm{Hex}](\diamond)$ and $\mathrm{K}_{3} \mathrm{PO}_{4}$ at $\mathrm{pH} 7.5$ (filled symbols) with the overall compositions used for the herbicides extraction (open symbols).

Table 2. Extraction efficiency using the ABS composed of choline alkanoate $\mathrm{IL}+\mathrm{K}_{3} \mathrm{PO}_{4}+\mathrm{H}_{2} \mathrm{O}$ at the same concentration of salt ( $\mathrm{pH} 7.5)$.

\begin{tabular}{|c|c|c|c|c|c|}
\hline \multirow{2}{*}{$\begin{array}{c}\mathrm{ABS} \\
\mathrm{IL} / \mathrm{K}_{3} \mathrm{PO}_{4}(\mathrm{pH} \text { 7.5) }\end{array}$} & \multirow{2}{*}{ IL (wt\%) } & \multirow{2}{*}{$\begin{array}{c}\mathrm{K}_{3} \mathrm{PO}_{4} \\
(w \mathrm{t} \%)\end{array}$} & \multicolumn{3}{|c|}{ Recovery \pm SD $^{a}(\%)^{b}$} \\
\hline & & & Simazine & Cyanazine & Atrazine \\
\hline \multirow{3}{*}[\mathrm{Cho}]{$[\mathrm{Pro}] / \mathrm{K}_{3} \mathrm{PO}_{4}$} & 35.37 & 9.92 & $88(5)$ & $92(5)$ & $86(5)$ \\
\hline & 39.60 & 10.04 & $93(4)$ & $92(4)$ & $97(4)$ \\
\hline & 43.98 & 9.85 & $96(4)$ & $92(4)$ & $98(4)$ \\
\hline \multirow{3}{*}[\mathrm{Cho}]{$[\mathrm{But}] / \mathrm{K}_{3} \mathrm{PO}_{4}$} & 34.35 & 10.11 & $52(5)$ & $54(5)$ & $58(5)$ \\
\hline & 39.70 & 10.16 & $69(6)$ & $68(5)$ & $77(5)$ \\
\hline & 44.82 & 9.98 & $68(6)$ & $62(5)$ & $75(6)$ \\
\hline \multirow{3}{*}[\mathrm{Cho}]{$[\mathrm{Hex}] / \mathrm{K}_{3} \mathrm{PO}_{4}$} & 35.23 & 9.94 & $60(6)$ & $67(6)$ & $71(4)$ \\
\hline & 39.99 & 10.18 & $66(5)$ & $73(5)$ & $83(5)$ \\
\hline & 44.58 & 10.09 & $75(4)$ & $80(5)$ & $93(4)$ \\
\hline
\end{tabular}

a SD: Standard Deviation; ${ }^{\mathrm{b}}$ Spiked concentration: $4.0 \mu \mathrm{g} / \mathrm{g}$.

The recoveries of the analytes were higher than $60 \%$ in all cases, and in most systems, the recoveries increased with increasing concentration of the ILs. Interestingly, the anion has a big effect on the extractions, and the highest recoveries were achieved in the ABS formed by [Cho][Pro] and neutral phosphate solution (recoveries higher than $85 \%$ ). Also, the analytes extracted by the ABS with [Cho][Pro] and neutral phosphate solution were better separated by HPLC without significant interference compared to the ABS formed by [Cho][But] or [Cho][Hex] and neutral phosphate solutions (chromatograms of the herbicides are shown in the Supplementary Materials). Therefore, the ABS formed by 
[Cho][Pro] and neutral phosphate solution is the preferred system for the extraction of these analytes.

\section{Materials and Methods}

\subsection{Materials and Chemicals}

The three triazine-based herbicides simazine, cyanazine, and atrazine ( $\geq 99.0 \%$ purity), choline hydroxide solution ( $46 \%$ in water), glacial acetic acid ( $\geq 99.7 \%$ purity), propionic acid ( $\geq 99.5 \%$ purity), butyric acid ( $\geq 99.0 \%$ purity), hexanoic acid ( $\geq 99.0 \%$ purity), octanoic acid ( $\geq 98.0 \%$ purity), phosphoric acid ( $\geq 85.0 \%$ purity), potassium phosphate tribasic ( $\geq 98.0 \%$ purity), sodium phosphate monobasic ( $\geq 99.0 \%$ purity), sodium phosphate dibasic ( $\geq 99.0 \%$ purity), acetonitrile (HPLC grade), and methanol (HPLC grade) were purchased from Sigma-Aldrich (Oakville, ON, Canada). All chemicals and reagents used were of analytical grade or higher and were used without further purification. The deionized (DI) water used in these experiments was obtained from a Millipore purified water system (Milli-Q Academic, MilliporeSigma, Oakville, ON, Canada).

Salt aqueous solutions were prepared at the desired $\mathrm{pH}$ (7.2 and 14.5) by mixing appropriate amounts of potassium phosphate tribasic and phosphoric acid in DI water. Neutral phosphate solution (27.52 $\mathrm{wt} \%$ ) was prepared with $9.9590 \mathrm{~g} \mathrm{~K}_{3} \mathrm{PO}_{4}$ and $3.00 \mathrm{~g}$ $\mathrm{H}_{3} \mathrm{PO}_{4}$ slowly added into $23.2292 \mathrm{~g}$ water, stirred until completely dissolved and cooled to room temperature. Alkaline phosphate solution (48.78 wt\%) was formed with $24.001 \mathrm{~g}$ $\mathrm{K}_{3} \mathrm{PO}_{4}$ added into $25.2015 \mathrm{~g}$ water and stirred to form a transparent solution. A similar procedure was followed to prepare the aqueous solutions of $\mathrm{Na}_{2} \mathrm{HPO}_{4}\left(\mathrm{pH}\right.$ 9.0), $\mathrm{NaH}_{2} \mathrm{PO}_{4}$ ( $\mathrm{pH}$ 3.3), $\mathrm{NaH}_{2} \mathrm{PO}_{4} / \mathrm{Na}_{2} \mathrm{HPO}_{4}$ (pH 5.5), and $\mathrm{NaH}_{2} \mathrm{PO}_{4} / \mathrm{Na}_{2} \mathrm{HPO}_{4}$ (pH 7.0). In all cases, the $\mathrm{pH}$ of the solutions was measured with a $\mathrm{pH}$ meter (Accumet XL 600, Fischer Scientific, Ottawa, ON, Canada).

Stock standard solutions of individual herbicides $(1.0 \mathrm{mg} / \mathrm{mL})$ were prepared in methanol. An intermediate mixture of the three herbicides $(100 \mu \mathrm{g} / \mathrm{mL}$ in methanol) was prepared by mixing the appropriate amount of the individual stock solutions, which was stored at $4{ }^{\circ} \mathrm{C}$. Standard solutions with lower concentrations $(10.0,5.0,2.0,1.0,0.5$, and $0.2 \mu \mathrm{g} / \mathrm{mL}$ ) were prepared daily in methanol by serial dilution and used for the calibration curve. A solution of $4.0 \mu \mathrm{g} / \mathrm{mL}$ of the three herbicides was used to study the recoveries and extraction efficiency of the ABS system.

\subsection{Synthesis and Characterization of ILs}

Choline alkanoate ILs were synthesized via neutralization of the base with the appropriate organic acids, following reported methods [42,43,57]. Briefly, 0.1 mol organic acid (glacial acetic acid, propionic acid, butyric acid, hexanoic acid, or octanoic acid) was added dropwise into an aqueous solution of choline hydroxide $(0.1 \mathrm{~mol})$. The mixture was stirred continuously using a magnetic stirrer (RZR 2051, Heidolph, Schwabach, Germany) for $12 \mathrm{~h}$ at room temperature. The obtained ILs were dried for $6 \mathrm{~h}$ under vacuum using a rotary evaporator (R-210, Büchi, Flawil, Switzerland), followed by freeze drying (Freezone 2.5, Labconco, Kansas City, MO, USA) for approximately 4 days.

To confirm the identity and purity of the synthesized ILs, $500 \mathrm{MHz}$ NMR spectroscopy (AVIIIHD 500, Bruker, Fällanden, Switzerland) and infrared spectroscopy (Attenuated total reflection (ATR) Fourier transform infrared (FTIR) spectrometer, Alpha, Bruker, Billerica, MA, USA) were used (spectra are included in the Supplementary Materials). Viscosity was measured using a VISCOlab 3000 viscometer (Cambridge Viscosity, Inc., Boston, MA, USA) at $25^{\circ} \mathrm{C}$. The water content of the choline ILs was measured using a Karl Fisher Titrator (C20, Mettler Toledo, Greifensee, Switzerland). The chemical properties of the synthesized ILs are shown in Table 3. 
Table 3. Chemical properties of the ILs used in this work.

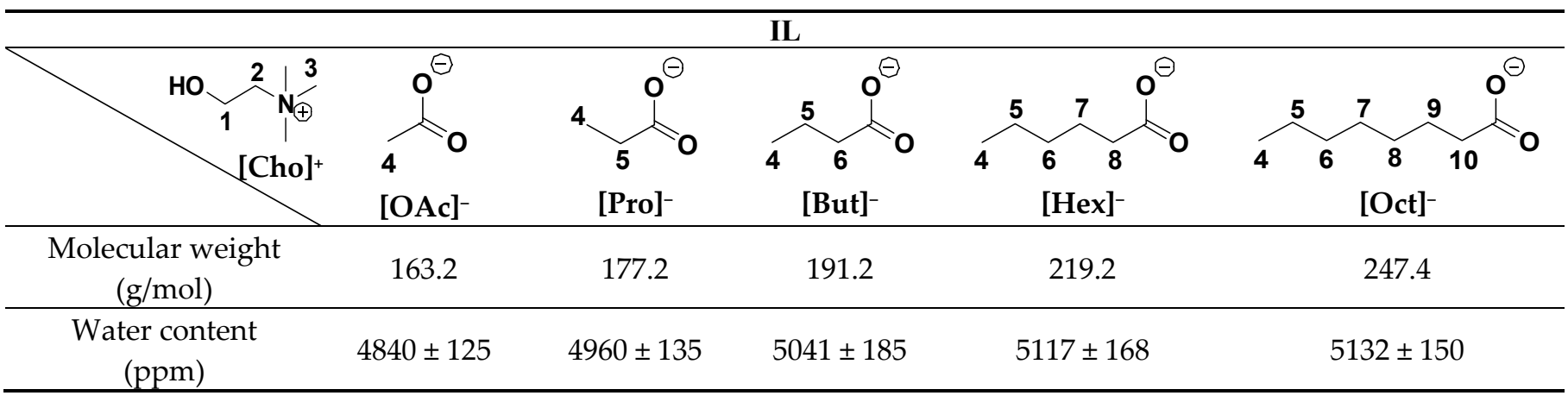

\subsection{Phase Diagrams}

\subsubsection{Determination of the Phase Diagrams}

The pure ILs $(25.00 \mathrm{~g})$ and $5.00 \mathrm{~g}$ water were added into a $100 \mathrm{~mL}$ beaker and mixed for $2 \mathrm{~min}$, forming an approximately $80 \mathrm{wt} \%$ of the IL solutions. Then, $0.550 \mathrm{~g}$ of the $80 \mathrm{wt} \%$ $\mathrm{IL}$ in water was placed in a test tube and an aqueous solution with a known concentration of phosphate was added dropwise until the mixture became cloudy. A known mass of DI water was then added to make the mixture clear again. This procedure was repeated until enough data was obtained to develop the binodal curve of the ABS. The mass fraction of the phase components was determined by weight quantification of all the components added to the tube within an uncertainty of $0.001 \mathrm{~g}$. The water content of the ILs was considered for the calculation of the compositions of the ABS mixtures. The experimental binodal data is provided in the Supplementary Materials.

\subsubsection{Determination of the Tie-Lines}

To determine the tie-lines (TLs), mixtures in the biphasic region were prepared in $10 \mathrm{~mL}$ glass vials, vigorously stirred, and allowed to achieve equilibrium by separation of the phases for $12 \mathrm{~h}$ at $25^{\circ} \mathrm{C}$. After phase separation, both the top (IL-rich solution) and bottom $\left(\mathrm{K}_{3} \mathrm{PO}_{4}\right.$-rich solution) phases were carefully collected. The compositions of the top and bottom phases were determined using the gravimetric method described by Merchuk et al. [58], and the concentrations of the IL components were confirmed using ${ }^{1} \mathrm{H}-\mathrm{NMR}$. Each TL was determined using the lever rule to calculate the relationship between the top mass phase composition and the overall system composition. The tie-line length (TLL) was calculated using Equation (1):

$$
\mathrm{TLL}=\sqrt{\left(\mathrm{X}_{\mathrm{T}}-\mathrm{X}_{\mathrm{B}}\right)^{2}+\left(\mathrm{Y}_{\mathrm{T}}-\mathrm{Y}_{\mathrm{B}}\right)^{2}}
$$

where $\mathrm{X}$ and $\mathrm{Y}$ are the weight fraction of the IL and salt, respectively; and the subscript $\mathrm{T}$ and B indicate the top and bottom phases, respectively. The TLL of the studied systems increased at alkali conditions (Table S3 in the Supplementary Materials).

\subsection{NMR Analysis}

Mixtures in the biphasic regions with mass fractions of 10\% neutral and 15\% alkaline phosphate salt, and with 35,40 , and $45 \%$ ILs, were prepared. Once phase separation was achieved (as described above), the top and bottom phases were separated. The IL aqueous solutions were prepared with concentrations in the range of 10-60 wt\%. Pure ILs, IL solutions, and the top and bottom phases collected from the ABS were loaded solventless in a flame-sealed capillary, and the ${ }^{1} \mathrm{H}$-NMR spectra were collected at $25^{\circ} \mathrm{C}$ using $d_{6}$-DMSO (dimethyl sulfoxide) as the external lock. Three sets of ${ }^{1} \mathrm{H}-\mathrm{NMR}$ determinations were performed and the chemical shift deviations of the protons of the ILs, as a function of water 
and IL concentrations, were determined. The chemical shift deviations of the different mixtures were calculated using Equations (2)-(4):

$$
\begin{gathered}
\Delta \delta_{1}=\delta(\text { IL solution })-\delta(\text { pure IL }) \\
\Delta \delta_{2}=\delta(\mathrm{ABS})_{\mathrm{IL}}-\delta(\text { pure IL }) \\
\Delta \delta_{1}=\delta(\mathrm{ABS})_{\mathrm{K} 3 \mathrm{PO} 4}-\delta(\text { pure IL })
\end{gathered}
$$

where the subscripts $\mathrm{K}_{3} \mathrm{PO}_{4}$ and IL denote the $\mathrm{K}_{3} \mathrm{PO}_{4}$ (bottom) or IL (top) phase in the ABS.

3.5. Extraction and Determination of the Target Herbicides Using the ABS Formed by ILs and pH 7.5 Phosphate Solutions

First, in $10.0 \mathrm{~mL}$ centrifuge tubes, known masses of $80 \mathrm{wt} \%$ IL, $24 \mathrm{wt} \% \mathrm{pH} 7.5$ phosphate solution (prepared as described in the section above), water, and the solution containing a mixture of the three target herbicides (spiked at $4.0 \mu \mathrm{g} / \mathrm{g}$ ), were sequentially added to form the ABS with different mass fractions of IL and $\mathrm{K}_{3} \mathrm{PO}_{4}$. The mixtures were stirred for $2 \mathrm{~min}$ by vortex at room temperature and then centrifuged at 4500 revolutions per minute (rpm) for $10 \mathrm{~min}$ (Sorvall ST8, Thermo Scientific, Waltham, MA, USA). After centrifugation, the centrifuge tube was left on the bench at room temperature for $2 \mathrm{~h}$ to form the ABS. The top phase was primarily comprised of IL, the analytes, and water, while the bottom phase was mainly comprised of phosphate salts and water. A blank sample was also prepared and treated according to the procedure mentioned above without adding the target herbicide solutions. The top and bottom phases were carefully separated using plastic syringes, and the volumes and masses of the top and bottom phases were recorded.

The top phases were filtered with a $0.45 \mu \mathrm{m}$ syringe filter membrane (VWR International, Ville Mont-Royal, QC, Canada) and injected into an HPLC for the separation and quantification of the herbicides. An Agilent 1260 series HPLC system with a quaternary pump, autosampler, and multiwavelength UV-Vis detector (Agilent Technologies, Santa Clara, CA, USA) was used for the determination of the studied herbicides. HPLC separations were performed using an XDB-C 18 column (Zorbax Eclipse $250 \mathrm{~mm} \times 4.6 \mathrm{~mm}, 5 \mu \mathrm{m}$, Agilent Technologies, Santa Clara, CA, USA) at $25^{\circ} \mathrm{C}$. Gradient elution was performed with water and acetonitrile (ACN) as the mobile phase for the separation of analytes. The analysis started with $30 \%(v / v)$ ACN to $50 \%$ in $20 \mathrm{~min}$. The column was then washed by increasing the proportion of ACN from $50 \%$ to $85 \%$ in $5 \mathrm{~min}$ and then to $95 \%$ in $1 \mathrm{~min}$, held at that composition for $4 \mathrm{~min}$, and then returning to $30 \% \mathrm{ACN}$, followed by a reequilibration time of $5 \mathrm{~min}$. The flow rate and the injection volume were $1.0 \mathrm{~mL} / \mathrm{min}$ and $20 \mu \mathrm{L}$, respectively. The detection wavelength was $220 \mathrm{~nm}$.

Recovery (R) of the target compounds was used to evaluate the extraction efficiency of the analytes by the ABS and was determined using Equation (5):

$$
\mathrm{R} \%=\frac{C_{I L} V_{I L}}{C_{0} V_{0}} \times 100 \%
$$

where $C_{I L}$ and $C_{0}$ are the concentration of the analytes in the IL (top) phase and the initial concentration of the analytes in the spiked sample solution, respectively; and $V_{I L}$ and $V_{0}$ are the volumes of the IL phase and the spiked sample solution, respectively.

\section{Conclusions}

In this manuscript, we demonstrated the ability of neutral and strong alkaline $\mathrm{K}_{3} \mathrm{PO}_{4}$ solutions to salt out choline alkanoate ILs to form ABS. The ability to form ABS with alkaline $\mathrm{K}_{3} \mathrm{PO}_{4}$ solutions decreased in the order [Cho][OAc] $\approx[\mathrm{Cho}][\mathrm{Pro}]>[\mathrm{Cho}][\mathrm{But}]>$ [Cho][Hex], while with neutral $\mathrm{K}_{3} \mathrm{PO}_{4}$ solution [Cho][OAc] would not form an ABS, and the other three ILs performed similarly. All biphasic regions of the ABS decreased with increases in $\mathrm{pH} .{ }^{1} \mathrm{H}-\mathrm{NMR}$ confirmed an anion exchange between the phases, especially at neutral $\mathrm{pH}$. Further studies are needed to fully understand the factors driving ABS 
formation using [Cho]-based ILs and inorganic salts at neutral $\mathrm{pH}$, including a complete understanding of the speciation occurring in each phase and the probability of anion exchange with the IL anion.

The ABS at neutral $\mathrm{pH}$ were then evaluated for herbicide extraction efficiency, due to the instability of the analytes in acidic or basic solutions. A higher affinity of the analytes (i.e., simazine, cyanazine, and atrazine) to the IL-rich phase was observed, with recoveries higher than $60 \%$ in all cases. Overall, the ABS formed with [Cho][Pro] and neutral $\mathrm{K}_{3} \mathrm{PO}_{4}$ solution exhibited the highest extraction recovery of the triazine herbicides, with recoveries higher than $90 \%$.

Supplementary Materials: Ionic liquids characterization $\left({ }^{1} \mathrm{H}-\mathrm{NMR},{ }^{13} \mathrm{C}-\mathrm{NMR}\right.$, and FTIR) (SI, Section 1, Figure S1); Binodal data of ABS (SI, Section 2, Figures S2-S4, Tables S1-S3); ${ }^{1} \mathrm{H}-\mathrm{NMR}$ spectra of the two phases in the ABS (SI, Section 3, Figures S5-S10, Table S4); Extraction and determination of herbicides by HPLC (SI, Section 4, Figures S11-S13, Table S5). Reference [59] is cited in the Supplementary Materials.

Author Contributions: Conceptualization, P.B., H.T. and R.D.R.; funding acquisition, R.D.R.; investigation, H.T.; methodology, P.B. and H.T.; project administration, R.D.R.; supervision, R.D.R.; writing—original draft, P.B. and H.T.; writing—review and editing, P.B., H.T. and R.D.R. All authors have read and agreed to the published version of the manuscript.

Funding: This research was funded by the Canada Excellence Research Chairs Program.

Data Availability Statement: Data is contained within the article or supplementary material. Additional data available on request to the authors.

Acknowledgments: H.T. is grateful for the financial support from the China Scholarship Council (CSC). This research was undertaken, in part, thanks to funding from the Canada Excellence Research Chairs Program.

Conflicts of Interest: The authors declare no conflict of interest.

Sample Availability: Samples of the compounds are not available from the authors.

\section{References}

1. Shao, M.; Zhang, X.; Li, N.; Shi, J.; Zhang, H.; Wang, Z.; Zhang, H.; Yu, A.; Tu, Y. Ionic liquid-based aqueous two-phase system extraction of sulfonamides in milk. J. Chromatogr. B. 2014, 961, 5-12. [CrossRef]

2. Sha, O.; Zhu, X.; Feng, Y.; Ma, W. Aqueous two-phase based on ionic liquid liquid-liquid microextraction for simultaneous determination of five synthetic food colourants in different food samples by high-performance liquid chromatography. Food Chem. 2015, 174, 380-386. [CrossRef]

3. Passos, H.; Sousa, A.C.; Pastorinho, M.R.; Nogueira, A.J.; Rebelo, L.P.N.; Coutinho, J.A.P.; Freire, M.G. Ionic-liquid-based aqueous biphasic systems for improved detection of bisphenol A in human fluids. Anal. Methods 2012, 4, 2664-2667. [CrossRef]

4. Dinis, T.B.; Passos, H.; Lima, D.L.; Esteves, V.I.; Coutinho, J.A.P.; Freire, M.G. One-step extraction and concentration of estrogens for an adequate monitoring of wastewater using ionic-liquid-based aqueous biphasic systems. Green Chem. 2015, 17, 2570-2579. [CrossRef]

5. Gutowski, K.E.; Broker, G.A.; Willauer, H.D.; Huddleston, J.G.; Swatloski, R.P.; Holbrey, J.D.; Rogers, R.D. Controlling the aqueous miscibility of ionic liquids: Aqueous biphasic systems of water-miscible ionic liquids and water-structuring salts for recycle, metathesis, and separations. J. Am. Chem. Soc. 2003, 125, 6632-6633. [CrossRef] [PubMed]

6. Flieger, J.; Czajkowska-Żelazko, A. Aqueous two phase system based on ionic liquid for isolation of quinine from human plasma sample. Food Chem. 2015, 166, 150-157. [CrossRef]

7. Lin, X.; Wang, Y.; Zeng, Q.; Ding, X.; Chen, J. Extraction and separation of proteins by ionic liquid aqueous two-phase system. Analyst 2013, 138, 6445-6453. [CrossRef]

8. Zeng, Q.; Wang, Y.; Li, N.; Huang, X.; Ding, X.; Lin, X.; Huang, S.; Liu, X. Extraction of proteins with ionic liquid aqueous two-phase system based on guanidine ionic liquid. Talanta 2013, 116, 409-416. [CrossRef] [PubMed]

9. Wang, X.; Wei, X.; Liu, J.; Liu, J.; Sun, D.; Du, P.; Ping, A. Study on the aqueous two-phase systems composed of surfactant, ionic liquid and water. Fluid Phase Equilib. 2013, 347, 1-7. [CrossRef]

10. Jiang, B.; Feng, Z.; Liu, C.; Xu, Y.; Li, D.; Ji, G. Extraction and purification of wheat-esterase using aqueous two-phase systems of ionic liquid and salt. J. Food Sci. Technol. 2015, 52, 2878-2885. [CrossRef]

11. Abraham, M.H.; Zissimos, A.M.; Huddleston, J.G.; Willauer, H.D.; Rogers, R.D.; Acree, W.E. Some novel liquid partitioning systems: Water-ionic liquids and aqueous biphasic systems. Ind. Eng. Chem. Res. 2003, 42, 413-418. [CrossRef] 
12. Holbrey, J.D.; Rogers, R.D. Ionic Liquids in Synthesis, 1st ed.; Wasserscheid, P., Welton, T., Eds.; Wiley-VCH: Weinheim, Germany, 2002; pp. 41-55.

13. Trujillo-Rodríguez, M.J.; Nan, H.; Varona, M.; Emaus, M.N.; Souza, I.D.; Anderson, J.L. Advances of ionic liquids in analytical chemistry. Anal. Chem. 2019, 91, 505-531. [CrossRef]

14. Ventura, S.P.M.; Sousa, S.G.; Serafim, L.S.; Lima, A.S.; Freire, M.G.; Coutinho, J.A.P. Ionic-liquid-based aqueous biphasic systems with controlled pH: The ionic liquid anion effect. J. Chem. Eng. Data 2012, 57, 507-512. [CrossRef]

15. Ventura, S.P.M.; Sousa, S.G.; Serafim, L.S.; Lima, A.S.; Freire, M.G.; Coutinho, J.A.P. Ionic liquid based aqueous biphasic systems with controlled pH: The ionic liquid cation effect. J. Chem. Eng. Data. 2011, 56, 4253-4260. [CrossRef]

16. Costa, S.P.; Martins, B.S.; Pinto, P.C.; Saraiva, M.L.M. Automated cytochrome c oxidase bioassay developed for ionic liquids' toxicity assessment. J. Hazard. Mater. 2016, 309, 165-172. [CrossRef] [PubMed]

17. Costa, S.P.; Pinto, P.C.; Lapa, R.A.; Saraiva, M.L.M. Toxicity assessment of ionic liquids with Vibrio fischeri: An alternative fully automated methodology. J. Hazard. Mater. 2015, 284, 136-142. [CrossRef]

18. Radošević, K.; Železnjak, J.; Bubalo, M.C.; Redovniković, I.R.; Slivac, I.; Srček, V.G. Comparative in vitro study of cholinium-based ionic liquids and deep eutectic solvents toward fish cell line. Ecotoxicol. Environ. Saf. 2016, 131, 30-36. [CrossRef] [PubMed]

19. Petkovic, M.; Ferguson, J.L.; Gunaratne, H.Q.N.; Ferreira, R.; Leitão, M.C.; Seddon, K.R.; Rebelo, L.P.N.; Pereira, C.S. Novel biocompatible cholinium-based ionic liquids-toxicity and biodegradability. Green Chem. 2010, 12, 643-649. [CrossRef]

20. Ventura, S.P.M.; e Silva, F.A.; Gonçalves, A.M.M.; Pereira, J.L.; Gonçalves, F.; Coutinho, J.A.P. Ecotoxicity analysis of choliniumbased ionic liquids to Vibrio fischeri marine bacteria. Ecotoxicol. Environ. Saf. 2014, 102, 48-54. [CrossRef]

21. Muhammad, N.; Hossain, M.I.; Man, Z.; El-Harbawi, M.; Bustam, M.A.; Noaman, Y.A.; Alitheen, N.B.M.; Ng, M.K.; Hefter, G.; Yin, C.-Y. Synthesis and physical properties of choline carboxylate ionic liquids. J. Chem. Eng. Data 2012, 57, 2191-2196. [CrossRef]

22. Rengstl, D.; Kraus, B.; Van Vorst, M.; Elliott, G.D.; Kunz, W. Effect of choline carboxylate ionic liquids on biological membranes. Colloids Surf. B 2014, 123, 575-581. [CrossRef]

23. Liu, X.; Li, Z.; Pei, Y.; Wang, H.; Wang, J. (Liquid+ liquid) equilibria for (cholinium-based ionic liquids+ polymers) aqueous two-phase systems. J. Chem. Thermodyn. 2013, 60, 1-8. [CrossRef]

24. Mourão, T.; Tomé, L.C.; Florindo, C.; Rebelo, L.P.N.; Marrucho, I.M. Understanding the role of cholinium carboxylate ionic liquids in PEG-based aqueous biphasic systems. ACS Sustain. Chem. Eng. 2014, 2, 2426-2434. [CrossRef]

25. Pereira, J.F.B.; Vicente, F.; Santos-Ebinuma, V.C.; Araújo, J.M.; Pessoa, A.; Freire, M.G.; Coutinho, J.A.P. Extraction of tetracycline from fermentation broth using aqueous two-phase systems composed of polyethylene glycol and cholinium-based salts. Process. Biochem. 2013, 48, 716-722. [CrossRef]

26. Quental, M.V.; Caban, M.; Pereira, M.M.; Stepnowski, P.; Coutinho, J.A.P.; Freire, M.G. Enhanced extraction of proteins using cholinium-based ionic liquids as phase-forming components of aqueous biphasic systems. Biotechnol. J. 2015, 10, 1457-1466. [CrossRef]

27. Tian, H.; Berton, P.; Rogers, R.D. Choline-based aqueous biphasic systems: Overview of applications. Fluid Phase Equilibr. 2019, 502, 112258. [CrossRef]

28. Shahriari, S.; Tomé, L.C.; Araújo, J.M.; Rebelo, L.P.N.; Coutinho, J.A.P.; Marrucho, I.M.; Freire, M.G. Aqueous biphasic systems: A benign route using cholinium-based ionic liquids. RSC Adv. 2013, 3, 1835-1843. [CrossRef]

29. Sintra, T.E.; Cruz, R.; Ventura, S.P.M.; Coutinho, J.A.P. Phase diagrams of ionic liquids-based aqueous biphasic systems as a platform for extraction processes. J. Chem. Thermodyn. 2014, 77, 206-213. [CrossRef]

30. Bogdanov, M.G.; Svinyarov, I. Analysis of acetylcholinesterase inhibitors by extraction in choline saccharinate aqueous biphasic systems. J. Chromatogr. A 2018, 1559, 62-68. [CrossRef]

31. Nie, L.; Song, H.; Yohannes, A.; Liang, S.; Yao, S. Extraction in cholinium-based magnetic ionic liquid aqueous two-phase system for the determination of berberine hydrochloride in Rhizoma coptidis. RSC Adv. 2018, 8, 25201-25209. [CrossRef]

32. Saravanan, S.; Rao, J.R.; Nair, B.U.; Ramasami, T. Aqueous two-phase poly (ethylene glycol)-poly (acrylic acid) system for protein partitioning: Influence of molecular weight, $\mathrm{pH}$ and temperature. Process Biochem. 2008, 43, 905-911. [CrossRef]

33. Neogi, P. Electrostatic effects on partitioning of proteins in aqueous two-phase systems: I. pH and charge equilibria. J. Colloid Interface Sci. 1993, 159, 261-274. [CrossRef]

34. Gündüz, U.; Korkmaz, K. Bovine serum albumin partitioning in an aqueous two-phase system: Effect of pH and sodium chloride concentration. J. Chromatogr. B: Biomed. Sci. Appl. 2000, 743, 255-258. [CrossRef]

35. Shang, Q.; Li, W.; Jia, Q.; Li, D. Partitioning behavior of amino acids in aqueous two-phase systems containing polyethylene glycol and phosphate buffer. Fluid Phase Equilib. 2004, 219, 195-203. [CrossRef]

36. Saravanan, S.; Rao, J.R.; Murugesan, T.; Nair, B.U.; Ramasami, T. Partition of tannery wastewater proteins in aqueous two-phase poly (ethylene glycol)-magnesium sulfate systems: Effects of molecular weights and pH. Chem. Eng. Sci. 2007, 62, 969-978. [CrossRef]

37. Kianmehr, A.; Pooraskari, M.; Mousavikoodehi, B.; Mostafavi, S.S. Recombinant D-galactose dehydrogenase partitioning in aqueous two-phase systems: Effect of $\mathrm{pH}$ and concentration of PEG and ammonium sulfate. Bioresour. Bioprocess. $2014,1,6$. [CrossRef]

38. Pusztai, A. Interactions of proteins with other polyelectrolytes in a two-phase system containing phenol and aqueous buffers at various pH values. Biochem. J. 1966, 99, 93. [CrossRef] [PubMed] 
39. Gautam, S.; Simon, L. Partitioning of $\beta$-glucosidase from Trichoderma reesei in poly (ethylene glycol) and potassium phosphate aqueous two-phase systems: Influence of $\mathrm{pH}$ and temperature. Biochem. Eng. J. 2006, 30, 104-108. [CrossRef]

40. Pereira, J.F.; Kurnia, K.A.; Cojocaru, O.A.; Gurau, G.; Rebelo, L.P.N.; Rogers, R.D.; Freire, M.G.; Coutinho, J.A.P. Molecular interactions in aqueous biphasic systems composed of polyethylene glycol and crystalline vs. liquid cholinium-based salts. Phys. Chem. Chem. Phys. 2014, 16, 5723-5731. [CrossRef] [PubMed]

41. Li, Z.; Liu, X.; Pei, Y.; Wang, J.; He, M. Design of environmentally friendly ionic liquid aqueous two-phase systems for the efficient and high activity extraction of proteins. Green Chem. 2012, 14, 2941-2950. [CrossRef]

42. Cheng, F.; Wang, H.; Chatel, G.; Gurau, G.; Rogers, R.D. Facile pulping of lignocellulosic biomass using choline acetate. Bioresour. Technol. 2014, 164, 394-401. [CrossRef] [PubMed]

43. Ninomiya, K.; Kohori, A.; Tatsumi, M.; Osawa, K.; Endo, T.; Kakuchi, R.; Ogino, C.; Shimizu, N.; Takahashi, K. Ionic liquid/ultrasound pretreatment and in situ enzymatic saccharification of bagasse using biocompatible cholinium ionic liquid. Bioresour. Technol. 2015, 176, 169-174. [CrossRef]

44. Tian, H.; Berton, P.; Rogers, R.D. Aqueous biphasic systems composed of random ethylene/propylene oxide copolymers, choline acetate, and water for triazine-based herbicide partitioning study. Solvent Extr. Ion Exch. 2018, 36, 602-616. [CrossRef]

45. Tian, H.; Xu, C.; Cai, J.; Xu, J. The aqueous biphasic system based on cholinium ionic liquids and nonionic surfactant and its application for triazine-based herbicides extraction. J. Chem. Thermodyn. 2018, 125, 41-49. [CrossRef]

46. Neves, C.M.S.S.; Ventura, S.P.; Freire, M.G.; Marrucho, I.M.; Coutinho, J.A.P. Evaluation of cation influence on the formation and extraction capability of ionic-liquid-based aqueous biphasic systems. J. Phys. Chem. B 2009, 113, 5194-5199. [CrossRef]

47. Li, C.X.; Han, J.; Wang, Y.; Yan, Y.S.; Pan, J.M.; Xu, X.H.; Zhang, Z.L. Phase Behavior for the Aqueous Two-Phase Systems Containing the Ionic Liquid 1Butyl3-methylimidazolium Tetrafluoroborate and Kosmotropic Salts. J. Chem. Eng. Data. 2009, 55, 1087-1092. [CrossRef]

48. Deive, F.J.; Rodríguez, A. (Liquid + liquid) equilibrium of aqueous biphasic systems composed of 1-benzyl or 1-hexyl-3methylimidazolium chloride ionic liquids and inorganic salts. J. Chem. Thermodyn. 2012, 54, 272-277. [CrossRef]

49. Zafarani-Moattar, M.T.; Hamzehzadeh, S. Effect of $\mathrm{pH}$ on the phase separation in the ternary aqueous system containing the hydrophilic ionic liquid 1-butyl-3-methylimidazolium bromide and the kosmotropic salt potassium citrate at T=298.15 K. Fluid Phase Equilib. 2011, 304, 110-120. [CrossRef]

50. E Silva, F.A.; Sintra, T.; Ventura, S.P.; Coutinho, J.A.P. Recovery of paracetamol from pharmaceutical wastes. Sep. Purif. Technol. 2014, 122, 315-322. [CrossRef]

51. Freire, M.G.; Claudio, A.F.M.; Araujo, J.M.M.; Coutinho, J.A.P.; Marrucho, I.M.; Lopes, J.N.C.; Rebelo, L.P.N. Aqueous biphasic systems: A boost brought about by using ionic liquids. Chem. Soc. Rev. 2012, 41, 4966-4995. [CrossRef] [PubMed]

52. Mourão, T.; Cláudio, A.F.M.; Boal-Palheiros, I.; Freire, M.G.; Coutinho, J.A.P. Evaluation of the impact of phosphate salts on the for mation of ionic-liquid-based aqueous biphasic systems. J. Chem. Thermodyn. 2012, 54, 398-405. [CrossRef]

53. Pismenskaya, N.; Laktionov, E.; Nikonenko, V.; El Attar, A.; Auclair, B.; Pourcelly, G. Dependence of composition of anionexchange membranes and their electrical conductivity on concentration of sodium salts of carbonic and phosphoric acids. $J$. Membr. Sci. 2001, 181, 185-197. [CrossRef]

54. DrugBank. Available online: https://go.drugbank.com/drugs/DB00122 (accessed on 3 March 2021).

55. Carboxylic Acids. Available online: https://crab.rutgers.edu/ alroche/Ch20.pdf (accessed on 3 March 2021).

56. Yang, X.J.; Qu, Y.; Yuan, Q.; Wan, P.; Du, Z.; Chen, D.; Wong, C. Effect of ammonium on liquid- and gas-phase protonation and deprotonation in electrospray ionization mass spectrometry. Analyst 2013, 138, 659-665. [CrossRef]

57. Yu, Y.; Lu, X.; Zhou, Q.; Dong, K.; Yao, H.; Zhang, S. Biodegradable naphthenic acid ionic liquids: Synthesis, characterization, and quantitative structure-biodegradation relationship. Chem.-Eur. J. 2008, 14, 11174-11182. [CrossRef] [PubMed]

58. Merchuk, J.C.; Andrews, B.A.; Asenjo, J.A. Aqueous two-phase systems for protein separation: Studies on phase inversion. J. Chromatogr. B: Biomed. Sci. Appl. 1998, 711, 285-293. [CrossRef]

59. Kalla, R.M.N.; Lim, J.; Bae, J.; Kim, I. Sulfated choline ionic liquid-catalyzed acetamide synthesis by grindstone method. Tetrahedron Lett. 2017, 58, 1595-1599. [CrossRef] 